\title{
Optimal controllers design for voltage control in off-grid hybrid power system
}

\author{
Harsha Anantwar ${ }^{1}$, Shanmukha Sundar ${ }^{2}$, B. R. Lakshmikantha ${ }^{3}$ \\ ${ }^{1,2}$ Department of Electrical and Electronics Engineering, Dayananda Sagar College of Engineering, India \\ ${ }^{3}$ Department of Electrical Engineering, Dayananda Sagar Academy of Technology and Management, India
}

\section{Article Info \\ Article history: \\ Received Aug 31, 2018 \\ Revised Apr 10, 2019 \\ Accepted Jun 26, 2019}

\section{Keywords:}

Enhanced bacterial foraging algorithm (EBFA)

Off-grid hybrid power system Voltage control

\begin{abstract}
Generally, for remote places extension of grid is uneconomical and difficult. Off-grid hybrid power systems (OGHPS) has renewable energy sources integrated with conventional sources. OGHPS is very significant as it is the only source of electric supply for remote areas. OGHPS under study has Induction generator (IG) for wind power generation, Photo-Voltaic source with inverter, Synchronous generator (SG) for Diesel Engine (DE) and load. Over-rated PV-inverter has capacity to supply reactive power. SG of DE has Automatic voltage regulator for excitation control to regulate terminal voltage. Load and IG demands reactive power, causes reactive power imbalance hence voltage fluctuations in OGHPS. To manage reactive power for voltage control, two control structures with Proportional-Integral controller (PI), to control inverter reactive power and SG excitation by automatic voltage regulator are incorporated. Improper tuning of controllers lead to oscillatory and sluggish response. Hence in this test system both controllers need to be tune optimally. This paper proposes novel intelligent computing algorithm, Enhanced Bacterial forging algorithm (EBFA) for optimal reactive power controller for voltage control in OGHPS. Small signal model of OGHPS with proposed controller is tested for different disturbances. Simulation results are compared with conventional method, proved the effectiveness of EBFA.
\end{abstract}

Copyright $@ 2019$ Institute of Advanced Engineering and Science. All rights reserved.

\section{Corresponding Author:}

Harsha Anantwar,

Department of Electrical and Electronics Engineering,

Dayananda Sagar college of Engineering,

Kumaraswamy Layout, Bangalore, 560078, India.

Email: hanantwar@yahoo.com

\section{INTRODUCTION}

The remote villages and small islands where it is difficult to have a connection from the central public utility, it is essential to have them energy solution which is cost efficient and environment friendly. Presence of large quantity of wind and solar energy observed in remote territories makes possible to utilize them to fulfill their energy requirement [1-2]. Remote area power supply system using mix of different renewable energy sources with conventional sources is called as off-grid hybrid power system (OGHPS). OGHPS is very significant as it is the only source of electric supply for isolated/remote area. The concern with renewable sources is that they are undependable, to realize dependable and quality power supply requires suitable and efficient control techniques.

The test system of OGHPS has power generation from Diesel, PV and Wind. The isolated power systems similar to test system have been already present in several small islands/ isolated communities [3]. Excitation system is employed for SG coupled to Diesel engine and the IG is used for wind power generation. An IG needs reactive power for its excitation. The reactive power absorbed by the IG during its operation varies with slip (wind speed). In OGHPS load and IG demand the reactive power. Deficient 
reactive power can cause severe fluctuations in system voltage; results in poor voltage profile stability. If voltage variation may go outside the tolerable limits, condition of power supply will not be acceptable for consumers. For reactive power management and voltage control, reactive power is needed to be balanced under all operating conditions .Hence, it is obligatory to have a sufficient capacity of reactive power source to be present in the OGHPS.

The earlier works reported in [4-10] for voltage and reactive power control of the wind diesel hybrid Power System are based on Static VAR Compensator (SVC) and Static synchronous compensator (STATCOM)] with load either static (exponential type) or static plus dynamic. Some good works have been reported, but, the parameters of the SVC/STATCOM controllers were optimized while controller parameters of automatic voltage regulator (AVR) of SG excitation control were fixed, hence cannot assure the efficient co-operative control. The work in [11] proposed voltage control of wind diesel hybrid power system based on $\mathrm{H} \infty$ loop shaping control of SVC and AVR with static load only. In their work, SVC and AVR controller gains were optimally tuned at the same time and performed agreeably. However the gains of the SVC and AVR controllers were optimized for arbitrary load change with a fixed reactive power request by the IG, which isn't reasonable. The work in [12] investigated the application of the model predictive control of SVC and AVR for voltage profile stability of the islanded hybrid wind-diesel power system with static load model only, not considered dynamic load. The work in [13] investigated artificial bee colony and gray wolf algorithm for optimization for reactive power control in hybrid power system with static load .In this work STATCOM and AVR controller are optimally tuned for step load change and performed very agreeably with static load model. However this work only considered static load as well as step load condition, which is not reasonable, in practical situation. From above discussion on reactive power control in off-grid hybrid power system, there is need for optimized coordinate control of reactive power sources (inverter and SG) under changing load (composite load- realistic load ) and wind power condition .

A PV inverter can control the active and non-active power within the bounds obliged by its apparent power [14] , is a fast acting, has superior transient performance, put off the need of a separate reactive power compensator, extra investment, PV-inverter is a convincing answer to address voltage regulation problem in OGHPS. PV inverter with surplus VAR capacity as a reactive power compensator for voltage control in OGHPS is proposed by author in previous work [15].

This paper presents coordinate control of PV inverter and AVR to control voltage and reactive power of OGHPS considering detailed composite load. Two control structure are incorporated, the first control structure objective is to control reactive power of inverter, and the second control is for controlling the SG excitation by AVR. The both control structures have PI controllers with a single input. To incorporate realistic features in this study, both controller parameters have been optimized at the same time. If controller parameters are not tuned effectively, may lead to oscillatory, sluggish control response and in the worst-case situation would result in collapse of system operation. There are many conventional methods and some methods based on minimizing performance index criteria available in the literature for controller tuning, but these methods do not give acceptable result when the condition is to optimize several gains of the controllers under varying operating conditions [16-18]. In the recent years, optimal tuning of controller parameters using intelligent swarm based computing techniques such as the Bacterial Foraging Algorithm (BFA) has grabbed attention of researcher $[19,20]$. Enhanced version of BFA (EBFA) is a novel method suggested in this work for optimal tuning controllers simultaneously. Optimal PI controller designing is mainly the outcome of minimizing a mathematical function (fitness function), which decides necessary control action.

In the view of the above discussion, this work focuses on voltage control of OGHPS considering the composite load model, with control parameters of the inverter and AVR tuned in coordination using EBFA when the system is subjected to varying disturbances

\section{Off-grid hybrid power system configurations (OGHPS)}

The OGHPS considered for the study is illustrated in Figure 1, of SG (Diesel Engine) with an excitation system with PI controller, IG (variable wind speed turbine), PV system interfaced with an inverter (PI controller) and a fixed capacitor bank (FC) to supply reactive power to IG at steady state. In this test system, power sources and load are assumed to close to each other. 


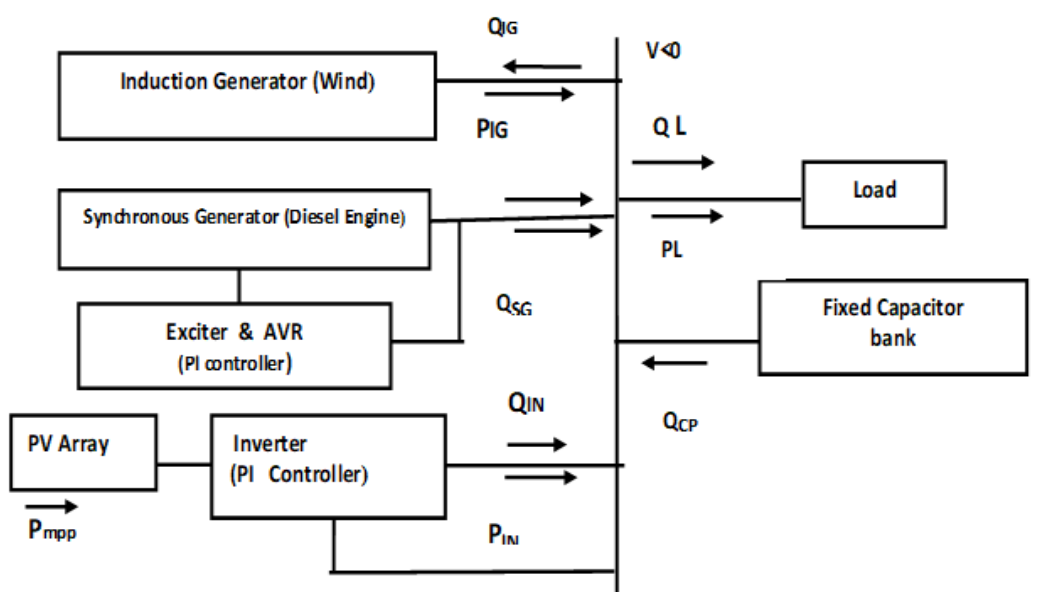

Figure 1. Test system (OGHPS)

\section{VOLTAGE - REACTIVE POWER EQUATION}

When the system is in a steady state condition, the power balance equation will be governed by

$$
Q_{S G}+Q_{I N}+Q_{C P}=Q_{L}+Q_{I G}
$$

When reactive power load demand $\left(\Delta Q_{L}\right)$ increases, and/or change in wind power input, the system generates reactive power is equal to $\Delta Q_{S G}+\Delta Q_{I N}$ due to the inverter and AVR of SG. The reactive power required for the system will also change due to change in voltage by $\Delta \mathrm{V}$. Then, the surplus reactive power in the system can be expressed as

$$
\Delta Q_{N}=\Delta Q_{S G}+\Delta Q_{I N}+\Delta Q_{C P}-\Delta Q_{L}-\Delta Q_{I G}
$$

The $\Delta \mathrm{Q}_{\mathrm{N}}$ net surplus reactive power, which due increase in electromagnetic energy absorption (Em) of the induction generator by $\frac{\mathrm{dEm}}{\mathrm{dt}}$ and increase in reactive load consumption, results in an increase of the system voltage, can be expanded as $[4,8,11]$

$$
\Delta Q_{N}=\frac{d E m}{d t}+D_{l v q} \Delta V(s)
$$

Where the $D_{l v q}$ (Composite load transfer function from the change in voltage to change in reactive power).

In power system dynamic load models are essential for examining the effect of non- linear loads in dynamic studies [21, 22]. The composite load provides a much more accurate representation of load response to voltage [23]. It represents the combined effect of aggregate of static and dynamic load (Induction motor) is shown in Figure 2. The participation ratio of static to dynamic load in composite load presentation for remotely located OGHPS is suggested as 4:1 in literature [24-26]. The OGHPS test system has a generation capacity of $400 \mathrm{KW}$ with composite loads of $300 \mathrm{KW}$. Composite load of $300 \mathrm{KW}$ has a static load of $240 \mathrm{KW}$ ( $80 \%$ of total load) and dynamic load of $60 \mathrm{KW}(20 \%$ of total load). $60 \mathrm{KW}$ dynamic load is modelled as an aggregate dynamic load model. The aggregate dynamic load of $60 \mathrm{KW}$ is developed considering set of seven Induction motor, of ratings ranging from $4 \mathrm{KW}$ to $20 \mathrm{KW}$, connected to same load bus.

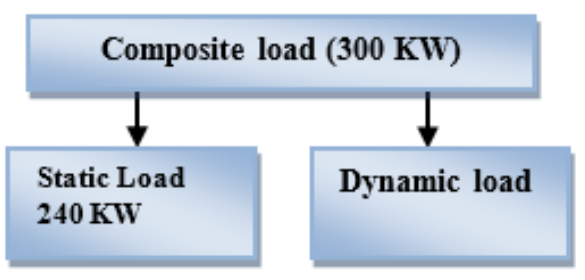

Figure 2. Composite load structure of OGHPS 
To take account the effect of the composite load in the system voltage- reactive power equation, the $D_{l v q}$ from (3), is expressed as

$$
D_{l v q}=D_{l v q-s t}+D_{l v q-d y}
$$

Where $D_{l v q-s t}$ is static load transfer function and $\mathrm{D}_{\text {lvq-dy }}$ is dynamic load transfer function.

From [4, 19], we can write as

$$
D_{\text {lvq-st }}=q\left(Q_{L s t} / V\right)
$$

Where $q$ is static load exponent and $Q_{L s t}$ static reactive power load.

Mathematical model of IM is represented by following five differential Equation of IM d-q axis, in the synchronous rotating frame [27].

$$
\begin{aligned}
& {\left[\begin{array}{c}
V_{q s} \\
V_{d s} \\
V_{q r} \\
V_{d r}
\end{array}\right]=\left[\begin{array}{cccc}
R_{s}+\frac{p}{\omega_{b}} X_{S} & \frac{\omega_{s}}{\omega_{b}} X_{S} & \frac{p}{\omega_{b}} X_{m} & \frac{\omega_{s}}{\omega_{b}} X_{m} \\
-\frac{\omega_{s}}{\omega_{b}} X_{S} & R_{s}+\frac{p}{\omega b} X_{S} & -\frac{\omega_{s}}{\omega_{b}} X_{m} & \frac{p}{\omega_{b}} X_{m} \\
\frac{p}{\omega_{b}} X_{m} & s \frac{\omega_{s}}{\omega_{b}} X_{m} & R_{R}+\frac{p}{\omega b} X_{r} & s \frac{\omega_{s}}{\omega_{b}} X_{r} \\
-s \frac{\omega_{s}}{\omega_{b}} X_{m} & \frac{p}{\omega_{b}} X_{m} & -s \frac{\omega_{s}}{\omega_{b}} X_{r} & R_{R}+\frac{p}{\omega_{b}} X_{r}
\end{array}\right]\left[\begin{array}{c}
I_{q s} \\
I_{d s} \\
I_{q r} \\
I_{d r}
\end{array}\right]} \\
& \frac{d \omega_{r}}{d t}=\frac{\omega_{b}}{2 H}\left(T_{E L}-T_{L}\right)
\end{aligned}
$$

Using (6) and (7), the transfer function of dynamic load $\mathrm{D}_{\text {lvq-dy }}$ of $60 \mathrm{KW} \mathrm{IM} \mathrm{load} \mathrm{is} \mathrm{developed}$

$$
D_{l v q-d y}=\frac{\left(0.0129 S^{5}+169 S^{4}+6.86 \mathrm{e} 04 S^{3}+2.9 \mathrm{e} 08 S^{2}+2.174 e 10 S+1.7 \mathrm{e} 11\right)}{\left(S^{5}+1.326 e 4 s^{4}+3.81 e 6 S^{3}+1.568 e 9 S^{2}+1.88 e 11 s+3.88 e 12\right)}
$$

Using (3), (4), (5) and (8) in (2), reactive power-voltage balance equation of OGHPS with the composite load model can be expanded as

$$
\Delta Q_{S G}+\Delta Q_{I N}+\Delta Q_{C P}-\Delta Q_{L}-\Delta Q_{I G}=\Delta V(s)\left(\left(\frac{V}{\omega X m}\right)+\left(D_{l v q-s t}+D_{l v q-d y}\right)\right)
$$

Small signal equation of reactive power of $\mathrm{SG}, \mathrm{IG}$ and $\mathrm{FC}$ and exciter voltage of $\mathrm{SG}$ are available in articles $[4,5,8,11,12,28]$. The incremental change in reactive power $\Delta Q_{I N}$ of PV inverter [15] is used in this work for modelling OGHPS. The simulation block diagram of OGHPS is shown in Figure 3

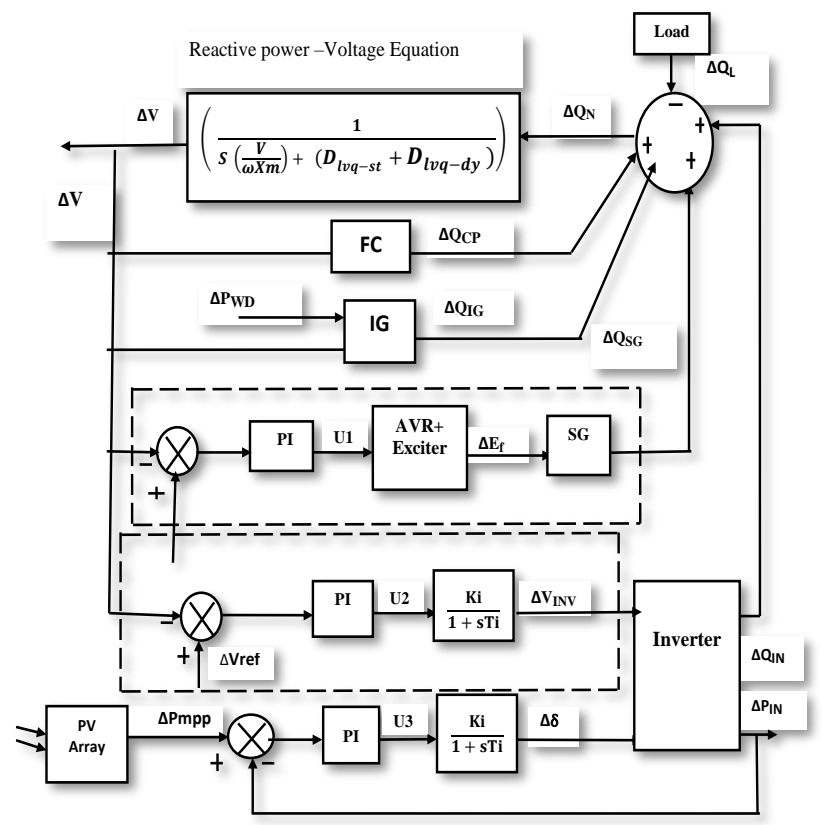

Figure 3. Small signal model of OGHPS 


\section{PI CONTROLLER PARAMETER OPTIMIZATION}

For coordinated voltage control, PI controller gain parameters $\left(\mathrm{K}_{\mathrm{P}}\right.$ and $\left.\mathrm{Ki}\right)$ of inverter and AVR, are to be optimized simultaneously. The two gain parameter of each controller formulates four dimensional optimization problem. The optimization task is to minimize the objective function. The objective function considered is an Integral of Time multiplied squared Error (ITSE), as given below.

$$
\begin{aligned}
& \operatorname{Min}(\mathrm{OB})=\operatorname{Min}(\mathrm{ITSE})=\operatorname{Min} \quad \int_{0}^{\infty}\left(\mathrm{t} \Delta \mathrm{V}(\mathrm{t})^{2}\right) \\
& \text { Subjected to: } k_{p}^{\min } \leq \mathrm{Kp} \leq k_{p}^{\max } \\
& k_{i}^{\text {min }} \leq \mathrm{Ki} \leq k_{i}^{\max }
\end{aligned}
$$

In this work conventional method of PI tuning is based on ITSE is employed due to its advantage that it penalizes less to initial errors to support rapid settling of the controlled output [29]. Figure 4 shows the optimal tuning of PI Controllers using EBFA.

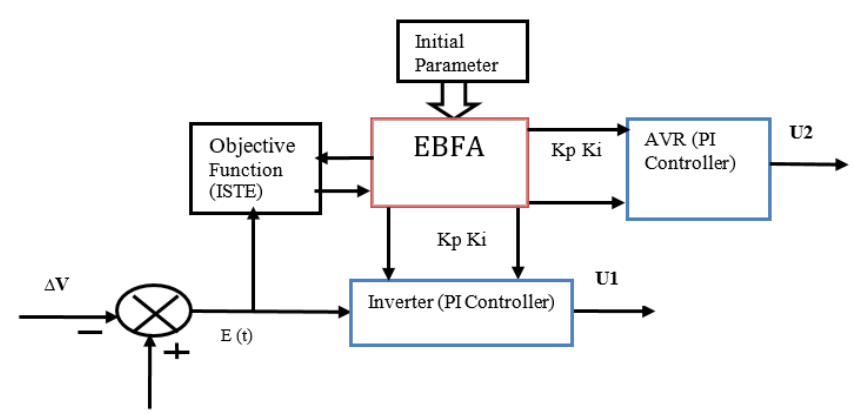

Figure 4. Optimal tuning of PI Controllers using EBFA

The control output from PI controller shown in Figure 4, is given by

$$
\mathrm{U}=\mathrm{K}_{\mathrm{P}} \Delta \mathrm{V}+\mathrm{K}_{\mathrm{I}} \int \Delta \mathrm{V} \mathrm{dt}
$$

Stepwise procedure of the performance index method of tuning controller parameters is as follows

Step 1. For a particular value of $\mathrm{Ki}$, evaluate ITSE, over a range of values of $\mathrm{Kp}$, and obtain optimum value of $\mathrm{Kp}$ for ITSE = min (ITSE)

Step 2. For optimum value of Kp obtained in step 1, evaluate ITSE, over a range of values of Ki and obtain value of $\mathrm{Ki}$ for ITSE $=\min (\mathrm{ITSE})$

Step 3. Kp and Ki obtained for other controller gains can be obtained by repeating the above steps.

This above procedure has been implemented sequentially in MATLAB, at a time one controller parameter is tuned while other controller parameters are kept constant. EBFA is applied to solve for optimization problem described in (10) for the constraints in (11). The constraints in (11), are chosen from the earlier work [15].

\section{ENHANCED BACTRIA FORAGING ALGORITHM (EBFA) FOR OPTIMAL TUNING OF CONTROLLER PARAMETERS}

BFA is a social system-based algorithm, based on foraging technique of E. coli bacteria [30]. BFA is proposed by [31], for optimization is called as original BFA. Foraging property of bacteria is modelled as optimization process. From the optimization point of view, in BFA, optimal value is the place, having highest food concentration [32].The random walk of bacteria with chemotactic step size in original BFA has disadvantages that, it may fail to converge to the global optimum, Hence there is a need to improve basic BFA to accelerate the convergence and better global optimum value. Several variants of the BFA have been developed to improve its optimum performance [33,34], one of the ways to improve basic BFA is to combine BFA and Particle Swarm optimization (PSO) algorithm, called as EBFA. This hybrid algorithm merges the aptitude of BFA to obtain a new solution due to dispersion process and the parallel search capability of PSO. In this algorithm, the velocity equation used in PSO, is used to update direction in 
the chemotaxis steps of bacteria. The movement of bacterium in the original BFA is random, hence need more chemotactic step to search for global optimum point. While in EBFA the random biased walk of bacterium is guided according to the global and the best positions based on PSO [35]. In PSO, velocity of particles is the due to the effect of their social interactions and local information. Incorporation of PSO is to improve search efficiency, solution accuracy and convergence speed.

In EBFA, at the starting of the search process, bacteria are randomly dispersed throughout the optimization domain, since the bacterial movement is not started, the local best position is its current position. The initial global best objective function value is the minimum value of objective function acquired by any of the bacterium in the population. The bacterium moves during chemotaxis process with a velocity updated using the velocity equation in PSO. The objective function of each bacterium is calculated after each step. During the process of searching for a global optimum point, bacterial undergoes reproduction and elimination-dispersal phenomenon. In the reproduction process, half population of bacteria having higher value of the objective function (ITSE) is eliminated, while the remaining half is split into two. To mimic the elimination-dispersal phenomenon, bacterium having small probability value is eliminated. To maintain the population, the replacements are initialized for eliminating bacterium. After completing sufficient chemotactic steps in the feasible domain, bacterium reaches to the point of highest food concentration (global optimum).

The computation procedure for EBFA to solve the optimization problem of finding optimal controller parameter is explained as

Step 1. Initialize the parameters, (Number of bacteria $(\mathrm{Nb})$, Chemotactic steps $\left(\mathrm{N}_{\mathrm{Ch}}\right)$, Limit of a swim $\left(\mathrm{N}_{\mathrm{sw}}\right)$, Reproduction steps $\left(\mathrm{N}_{\mathrm{Rp}}\right)$, Elimination-dispersal events $\left(\mathrm{N}_{\mathrm{ELD}}\right)$,), the probability that each bacteria will be eliminated/dispersed ( $\mathrm{P}_{\mathrm{ELD}}$ ), PSO parametrs are $\mathrm{C}_{1}, \mathrm{C}_{2}$ and $\omega \mathrm{min}, \omega \mathrm{max}$.

Step 2. Elimination-dispersal loop for $E d=1$ to $N_{E L D}$

Step 3. Reproduction loop for $\mathrm{R}=1$ to $\mathrm{N}_{\mathrm{RP}}$,

Step 4. Chemotactic loop counter for $\mathrm{J}=1$ to $\mathrm{N}_{\mathrm{Ch}}$

Step 5. For $\mathrm{I}=1$ to $\mathrm{N}_{\mathrm{b}}$,

a. Compute the objective function, $\operatorname{ITSE}(I, J, R, E d)$ for every bacterium, save as ITSElast $=$ ITSE $(I, J, R, E d)$, ( compares other best values which may found during a run )

b. Tumble- Generate a random vector $\Delta(\mathrm{I}) \in \mathcal{R}^{a}$, in the a dimensional search space $(\mathrm{a}=4)$, for each element to be optimized $\Delta_{\mathrm{k}}(\mathrm{I}), \mathrm{k}=1,2,3,4$.compute the position of $I^{\text {th }}$ bacterium in the direction of the tumble as $\mathrm{P}(I, J+1, K, E d)=\mathrm{P}(I, J, R, E d)+\mathrm{S}(I)) \Delta(\mathrm{I})$. The step size ' $\mathrm{S}$ ' value is fixed.

c. Compute $\operatorname{ITSE}(I, J+1, R, E d)$ for every bacterium for new position $\mathrm{P}(I, J+1, R, E d)$,

d. Initialize swim loop counter $\mathrm{m}=0$

- While $\mathrm{m}<N_{S W}$

If $\operatorname{ITSE}(I, J+1, R, E d)<\operatorname{ITSE}_{\text {last }}$ (bacterium moving in the right the direction) then $\mathrm{ITSE}_{\text {last }}=\operatorname{ITSE}(I, J+1, R, E d)$, calculate the position of bacterium as

$\mathrm{P}(I, J+1, R, E d)=\mathrm{P}(I, J+1, R, E d)+\mathrm{S}(I) \Delta(\mathrm{I})$.

- Else, $\mathrm{m}=\mathrm{N}_{\mathrm{SW}}$ (End of loop)

e. If $I \neq N b$ to step $4 \mathrm{~b}$ for a next bacterium $(I=I+1)$

Step 6. Calculate the local best position and global best position for each bacterium

Step 7. Update each bacterium velocity using equation of PSO as

$\vartheta(J+1)=\omega \quad \vartheta \quad(J)+C_{1} R_{1}$ (localbestposition - currentposition) $+C_{2} R_{2}$ (globalbestposition currentposition), updated velocity of each bacterium is the value of vector $\Delta$ (I) for next chemotactic step.

Step 8. If $J<N_{C h}$, go to step 4

Step 9. Reproduction

- Calculate the health of the each bacterium after completing $\mathrm{N}_{\mathrm{Ch}}$, chemotactic steps. $\mathrm{ITSE}_{\text {health }}^{\mathrm{I}}=\sum_{\mathrm{J}=1}^{\mathrm{N}_{\mathrm{Ch}+1}} \operatorname{ITSE}(\mathrm{I}, \mathrm{J}, \mathrm{R}, \mathrm{Ed})$. Sort ITSE $\mathrm{I}_{\text {health }}^{\mathrm{I}}$ in ascending order. The bacteria with

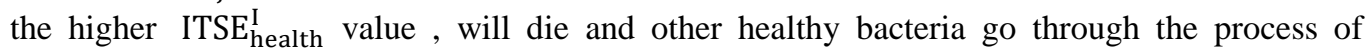
reproduction to the maintain population.

Step 10. If $\mathrm{R}<N_{R P}$ then go to step (2),

Step 11. Elimination-dispersal: For I $=1$ to $\mathrm{Nb}$, bacterium having probability value less than $P_{E D}$, get eliminated and dispersed to a random position in the search space and other bacterium maintain their position

Step 12. If Ed < $N_{E L D}$, go to step 2, else end

Based on the above steps of EBFA, a program is written in MATLAB for optimal controller parameters. The parameter of EBFA is given in Appendix 1. 


\section{SIMULATION RESULTS AND DISCUSSION}

The mathematical model of components of OGHPS based on the reactive power balance equation, is build in simulink and simulated in Simulnik with PI controller parameters of PV inverter and AVR are optimally tuned using EBFA and conventional method. OGHPS simulation model is tested under different disturbance cases. (Step change and random change in load plus wind power). Transient responses of state variables for different disturbance conditions are presented in this section as follows,

a. Case 1. Transient performance of the system for step disturbance of $5 \%$ of reactive load demand $\mathrm{Q}_{\mathrm{L}}$

The time responses of deviation in state variable such as load voltage, inverter reactive power, SG reactive power and IG for a 5\% step increase in reactive load at $\mathrm{t}=0 \mathrm{Sec}$, at the constant wind power input to the IG and $1 \%$ increase in PV irradiance and temperature are illustrated in Figure 10 (a)-(d). The system is in steady state, prior to change in reactive load demand. From the Figure 10 (a)-(d), it is observed that inverter provides dynamic support of reactive power to mitigate the load disturbance, while the AVR of synchronous generator initially support by taking action to maintain voltage following the disturbance. From the responses shown in Figure 10 (a)-(d), it is evident that control characteristics such as Peak value, Oscillation and settling of state variables are improved considerably in case of EBFA based Optimal PI controllers.

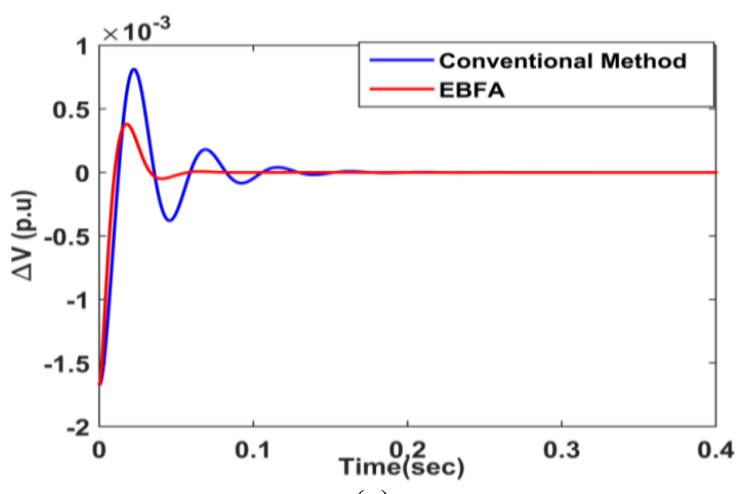

(a)

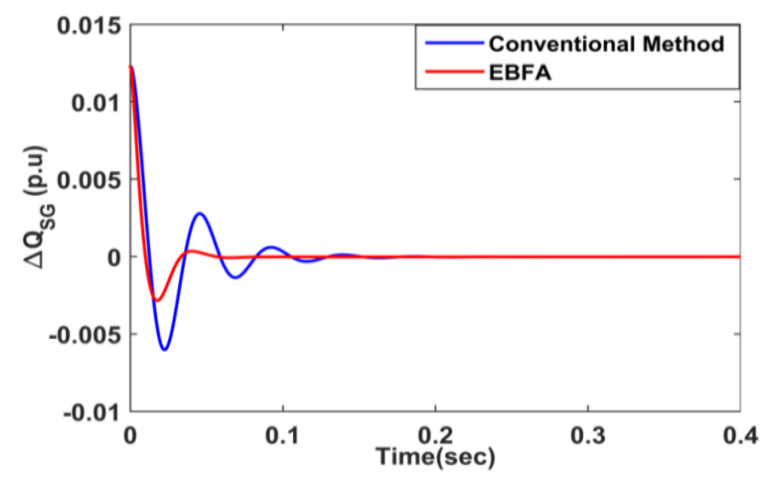

(c)

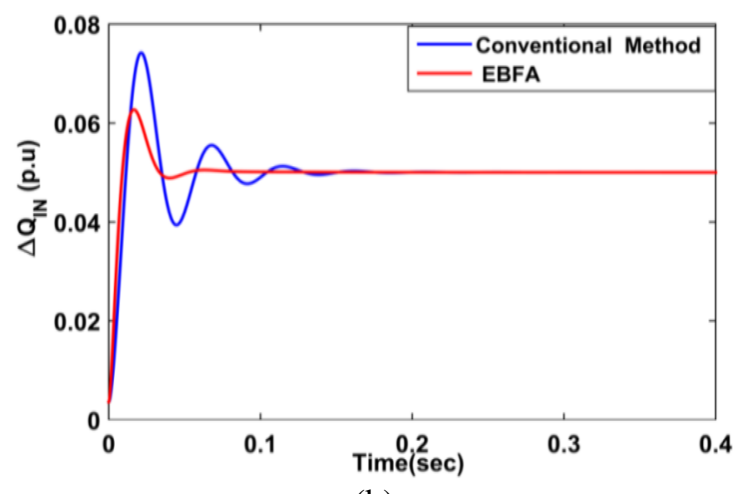

(b)

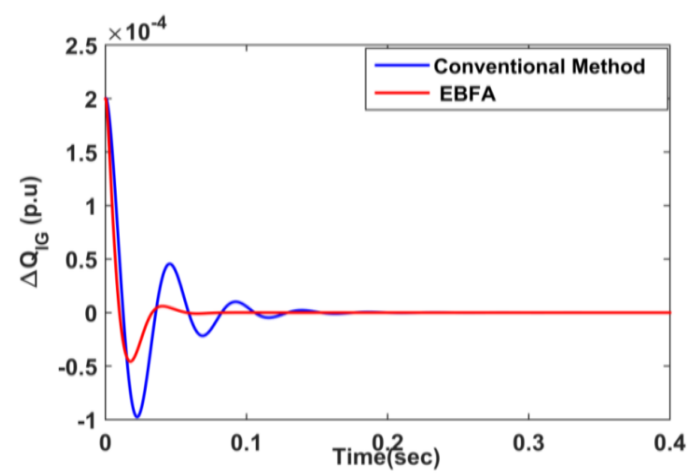

(d)

Figure 10 (a). Transient response of $\Delta \mathrm{V}$, (b) Transient response of $\Delta \mathrm{Q}_{\mathrm{IN}}$,

(c) Transient response of $\Delta \mathrm{Q}_{\mathrm{SG}}$, (d) Transient response of $\Delta \mathrm{Q}_{\mathrm{IG}}$

b. Case 2. Transient performance of the system for $10 \%$ Step disturbances in reactive load demand as well as wind power

The time domain response of deviation in system state variable such as voltage and reactive power of the inverter, SG and IG for the step increase of 0.1 p.u. (10\% from the initial steady state value) in both reactive power loading and wind power, with $1 \%$ increase in PV irradiance and temperature at $\mathrm{t}=0 \mathrm{Sec}$, is illustrated in Figure 11 (a)-(d). As wind speed fluctuates, mechanical wind power input to IG changes, slip changes, hence reactive power demand of IG changes. The increase in the reactive power of demand is $\Delta \mathrm{Q}_{\mathrm{IG}}+\Delta \mathrm{Q}_{\mathrm{L}}$. Due to inverter and AVR, the reactive power generated in the system varies to fulfil the demand, to suppress the voltage deviation. 
From Figure 11 (a)-(d), it is observed that state variables regained steady state condition quickly with EBFA control compared to Conventional method. The response of the state variables $\Delta \mathrm{V}$ and $\Delta \mathrm{Q}_{\mathrm{SG}}$, becomes zero are as shown in Figure 11 (a) and (c). The Peak value and Oscillation of state variables are reduced considerably in the case of EBFA.

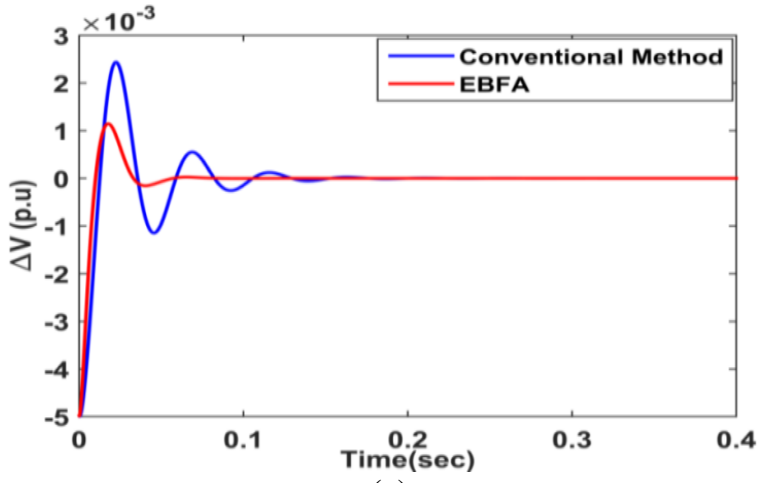

(a)

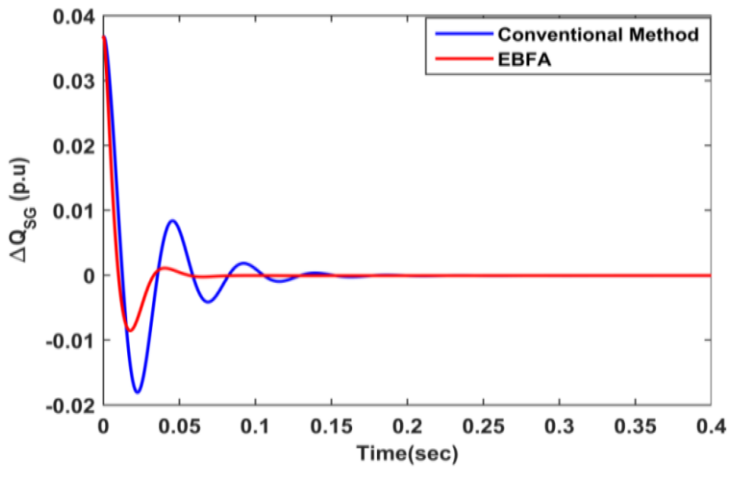

(c)

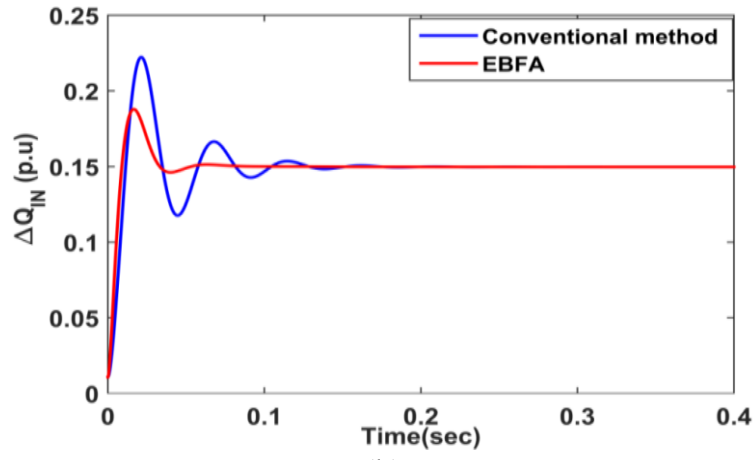

(b)

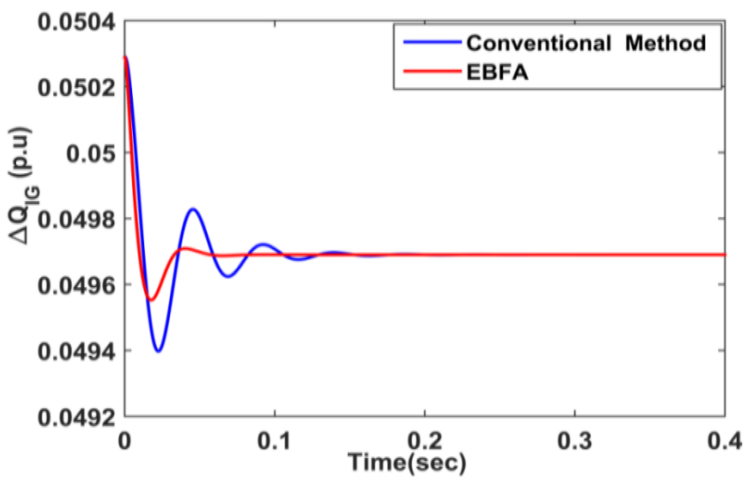

(d)

Figure 11 (a). Transient response of $\Delta \mathrm{V}$, (b) Transient response of $\Delta \mathrm{Q}_{\mathrm{IN}}$,

(c) Transient response of $\Delta \mathrm{Q}_{\mathrm{SG}}$, (d) Transient response of $\Delta \mathrm{Q}_{\mathrm{IG}}$

c. Case 3. Transient performance of the system for random disturbance in reactive load demand as well as wind power input to IG.

In OGHPS system, the load is largely residential and commercial type. The load is fluctuating and random. Wind power is intermittent in nature due to fluctuating wind speed. The random variation in load and wind power is as shown in Figure 12 (a) and (b). This case also considers a $1 \%$ increase in PV irradiance and temperature the transient responses of state variable for random variation in reactive load and wind power are illustrated in Figure 12 (c)-(f). The voltage deviation due to random disturbances is suppressed by the action of inverter and AVR, by generating required reactive power to balance system reactive power. In this system, as the PV inverter is oversized to increase its reactive power capacity, supports the system for reactive power even when there is change in PV real power from the PV array.

It is clear from Figure 12(c)-(f), that co-ordinately optimized PI controllers by EBFA methods, exhibited better dynamic reactive power control outcome compared to conventional tuning the PI controller under random disturbance condition. The optimal values of controller parameters obtained by EBFA for the case 2 are given in the Table 1. The maximum voltage deviation (p.u) for $10 \%$ reactive loading plus $10 \%$ wind power change (case 2) for EBFA control and conventional control is presented in Table 2. Comparison of OGHPS system state variables performance for EBFA tuned controllers (Inverter and AVR) with conventional method tuned controllers (Inverter and AVR) in terms of settling time is presented in Figure 13. 


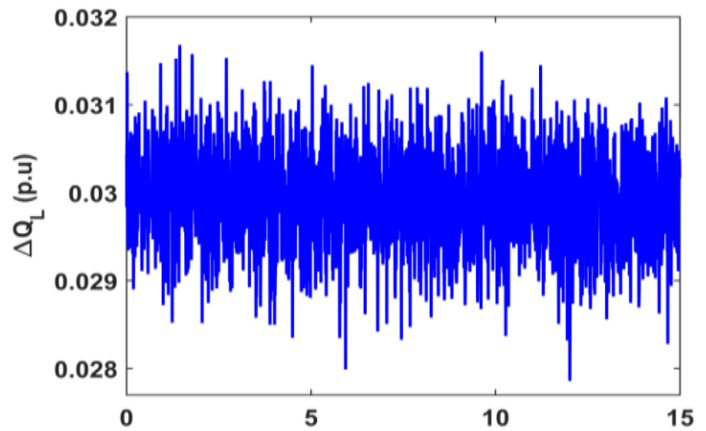

(a)

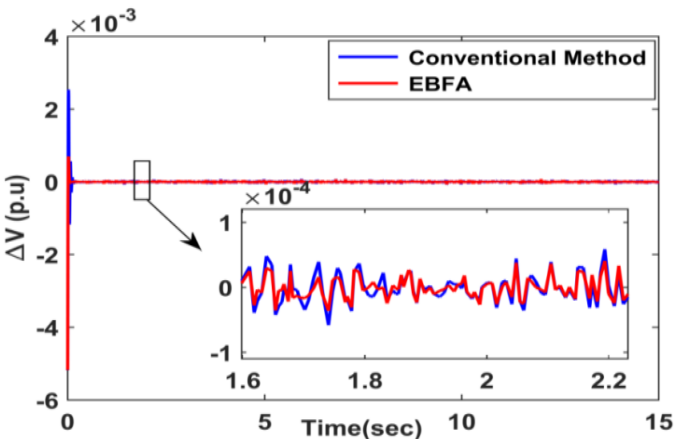

(c)

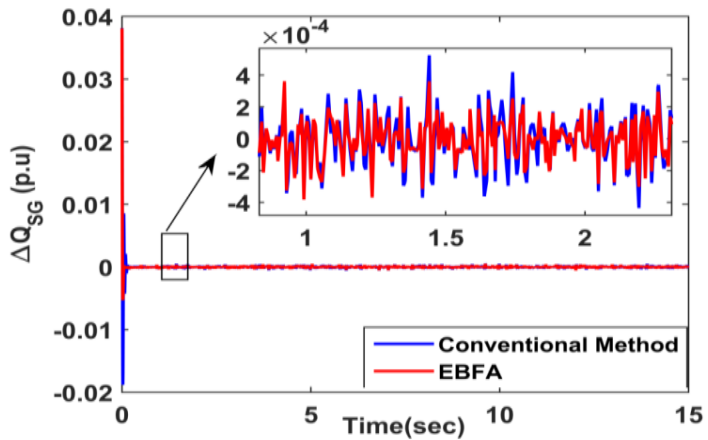

(e)

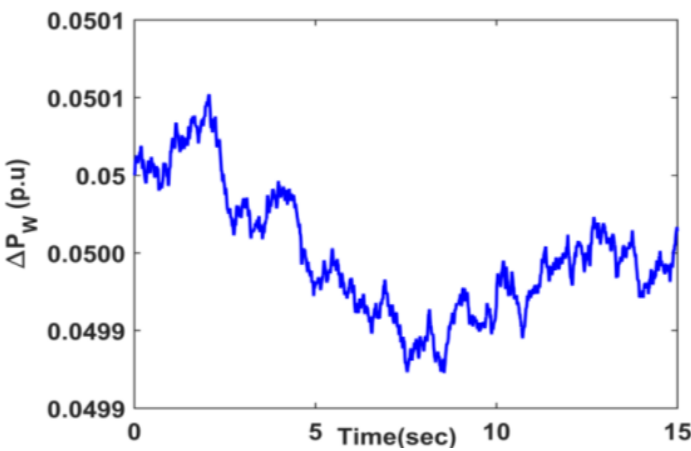

(b)

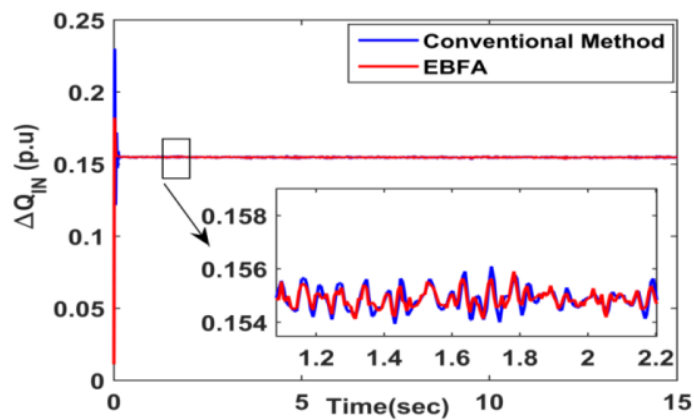

(d)

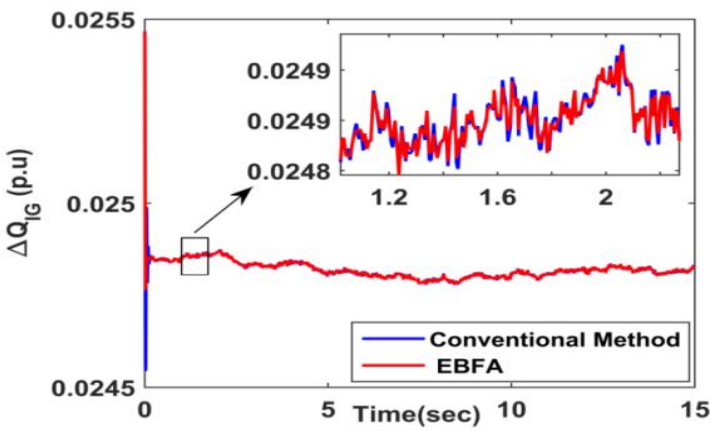

(f)

Figure 12 (a). Random disturbance in reactive power load, (b) Random deviation in wind power input to IG, (c) Transient response of $\Delta \mathrm{V}$, (d) Transient response of $\Delta \mathrm{Q}_{\mathrm{IN}}$, (e) Transient response of $\Delta \mathrm{Q}_{\mathrm{SG}}$,

(f) Transient response of $\Delta \mathrm{Q}_{\mathrm{IG}}$

Table 1. Inverter and AVR controller parameters for case 2

\begin{tabular}{ccccc}
\hline Optimization method & \multicolumn{2}{c}{ Inverter } & \multicolumn{2}{c}{ AVR } \\
& $\mathrm{Kp}$ & $\mathrm{Ki}$ & $\mathrm{Kp}$ & $\mathrm{Ki}$ \\
\hline EBFA & 21.417 & 5552.176 & 25.97 & 50 \\
Conventional & 13.5 & 4800 & 10 & 30 \\
\hline
\end{tabular}

Table 2. Maximum voltage deviation in p.u for case 2

\begin{tabular}{ccc}
\hline Disturbance condition & EBFA & Conventional \\
\hline Case 1 & 0.000223 & 0.00082 \\
Case2 & 0.0006731 & 0.002436 \\
\hline
\end{tabular}




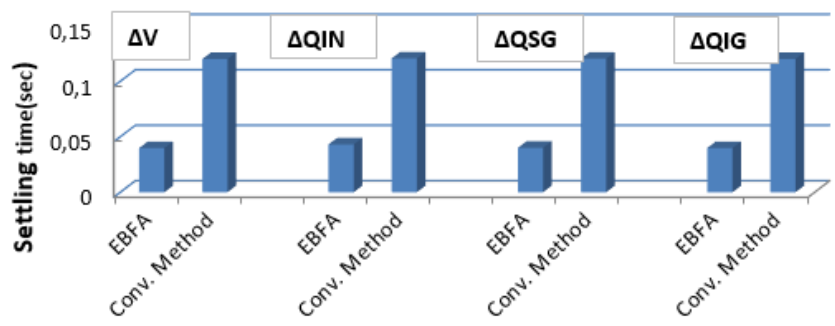

Figure 13. Settling time for state variables of the OGHPS (case 2)

\section{CONCLUSION}

Voltage /VAR control of OGHPS considering a composite load model with optimally designed controllers, for the inverter and AVR is investigated for the small signal voltage profile stability. The system model based on reactive power - voltage characteristics OGHPS considering a composite load model is build in Simulnik. In order to have coordinated control inverter and AVR controller parameters are optimized simultaneously using EBFA.

Simulation is carried out under step change in load disturbances of different magnitude. Simulation is also carried out for realistic change in load and wind power i.e randomly changing reactive load demand and wind power, to study the dynamic performance of the system with EBFA based optimal tuned controllers of inverter and AVR. From the simulation results presented in above section, it is observed that the dynamic performance of system state variables is improved for EBFA optimized controllers as compared to conventional method. The response of EBFA optimized controllers is enhanced in terms of peak deviation and settling time for all system state variables.

From this work, it can be concluded that EBFA tuned PI controller of inverter and AVR have a better control effect to suppress voltage fluctuation by balancing system reactive power. EBFA controlled OGHPS worked robust even under arbitrary varying disturbance condition, hence dynamic performance of OGHPS is enhanced. The main contribution of work presented in this paper are:

- Consideration of composite load as realistic load in OGHPS

- Coordinated reactive power control of PV inverter and AVR

- Design of optimal controller of PV inverter and AVR for step change as well as random change in composite load.

This work has opened a research area for reactive control to maintain the voltage by optimum control of PV inverter and AVR of SG in a small off-grid hybrid power system having composite load.

\section{REFERENCES}

[1] J. Kaldellis et al, Stand-Alone and Hybrid Wind Energy Systems Technology, energy storage and applications, Woodhead Publishing Limited, Jul 2010.

[2] M. R. Patel, Wind and solar power system: Design, Analysis, and operation, 2nd Edition, CRC Press, Boca Raton, FL, USA, 2005.

[3] HI. Mickal, "100 kW Photovoltaic Power Plant for Kythnos Island," Proc. Of Fifth EC Photovoltaic Conference, Oct 1983, pp. 490-494.

[4] R. C. Bansal, "Automatic Reactive-Power Control of Isolated Wind-Diesel Hybrid Power Systems," IEEE Transactions on Industrial Electronics, vol. 53, no. 4, Aug 2006.

[5] Sharma, P., Saxena, N. K., and Bhatti, T. S., "Study of autonomous hybrid power system using SVC and STATCOM," Proceedings of ICPS Kharagpur, India, Dec 2009.

[6] Jinning Liu, Li Zhang, Man Cao, "Power management and synchronization control of renewable energy microgrid based on STATCOM," IEEE Conference and Expo on Transportation Electrification Asia-Pacific, 2014.

[7] D. Menniti, A. Pinnarelli, N. Sorrentino, "An hybrid PV-wind supply system with D-Statcom interface for a waterlift station," International Symposium on Power Electronics Electrical Drives Automation and Motion (SPEEDAM), Jun 2010

[8] Saxena N. K., Kumar A., "Dynamic Reactive Power Compensation and Cost Analysis for Isolated Hybrid Power System," Electric Power Components and Systems, vol. 45, no. 18, pp. 2034-204., 2017.

[9] Hussain D. C. Das, and N. Sinha, "Reactive power performance analysis of dish-Stirling solar thermal-diesel hybrid energy system," IET Renew. Power Gen., vol. 11, no. 6, pp. 750-762, May 2017.

[10] Banerjee, A., Guchhait, P. K., Mukherjee, V., \& Ghoshal, S. P., "Seeker optimized SVC-PID controller for reactive power control of an isolated hybrid power system," Energy Systems. Springer-Verlag GmbH Germany, part of Springer Nature, 2018.

[11] Vachirasricirikul S., Ngamroo I., Kaitwanidvilai S., "Coordinated SVC and AVR for robust voltage control in a hybrid wind-diesel system”, Energy Convers. Manage, vol. 51, no. 12, pp. 2383-2393, 2010. 
[12] Ahmed M. K., Almoataz Y. A., "Functional Predictive Control for Voltage Stability Improvements of Autonomous Hybrid Wind-Diesel Power System,” Electric Power Components \& Systems, vol. 42, no. 8, pp. 831-844, 2014.

[13] Shiraliyan M., et al., "Automatic reactive power control of isolated wind-diesel hybrid power system using artificial bee colony and gray wolf optimization," International Journal of Green Energy, pp. 1-16., 2018.

[14] Jahangiri P., Aliprantis D.C, "Distributed volt/var control by PV inverters," IEEE Trans. Power Syst., vol. 28, no. 3, pp. 3429-3439, 2013.

[15] Harsha A., B R Lakshmikantha and Shanmukha S., "Fuzzy self tuning PI controller based inverter control for voltage regulation in off-grid hybrid power system," Elsevier, Energy Procedia, vol. 117 pp. 409- 416, 2017.

[16] Wang Y, Shao H. ,’Optimal tuning for PI controller," Automatica, vol. 36, pp. 147-52, 2000.

[17] Zhuang M., and D. P. Atherton, "Tuning of PID controllers with integral performance criteria," Proceedings of IEEE Control' '91, vol. 1, no. 332, pp. 481-486, 1991.

[18] Chopra Vikram, Singla Sunil K, Dewan Lillie, "Comparative analysis of tuning a PID controller using intelligent methods," Acta Polytechnica, Hungarica, vol. 11, no. 8, pp. 235-49, 2014.

[19] Jieming Ma, Ziqiang Bi, Tiew On Ting, Shiyuan Hao, Wanjun Hao, "Comparative performance on photovoltaic model parameter identification via bio-inspired algorithms," Solar Energy, vol. 132, pp. 606-616, Jul 2016.

[20] ChenYu-Peng, et al, "A novel bacterial foraging optimization algorithm for feature selection," Expert Systems with Applications, vol. 83, pp. 1711-1715, Oct 2017.

[21] IEEE Task Force on load representation for dynamic performance, "Load Representation for Dynamic Performance Analysis," IEEE Trans. On Power Systems, vol. 8, pp. 472-482, May 1993.

[22] Stojanovi Dobrivoje P, Korunovi Lidija M, Milanovi JV, "Dynamic load modeling based on measurements in medium voltage distribution network," Electric Power Syst Res, vol. 78, pp. 228-38, 2008.

[23] Kosterev D, Meklin A, "Load modeling in WECC," Power Systems Conference and Exposition, 2006, pp. 576-581.

[24] P Tania, "Composite Load Model Decomposition: Induction Motor Contribution," Ph.D. Dissertation. Faculty of Built Environment and Engineering, School of Engineering Systems, Queensland University of Technology, 2009.

[25] Fahmy O.M., Attia A.S., Badr M.A.L., "A novel analytical model for electrical loads comprising static and dynamic components," Electric Power System Research, vol. 77, pp. 1249-1256, 2007.

[26] Kim Byoung Ho, Kim Hongrae, Lee Byoungjun., "Parameter estimation for the composite load model," Journal of International Council on Electrical Engineering, vol. 2, pp. 215-218, 2012.

[27] Krause P C, Wasynczuk O, Sudhoff S D, Analysis of Electric Machinery and Drive Systems, 2nd Ed. New York: John Wiley \& Sons Publication-IEEE Press, 2002.

[28] Kothari D.P., Nagrath I.J., Electric Machines, Tata-McGraw-Hill, India D.S. 2006.

[29] Carrasco and M.E. Salgado, "Optimal multivariable controller design using an ITSE performance index," International Journal of Control, vol. 83, no. 11, Nov 2010.

[30] ChenYu-Peng, LiYing, Wang Gang, ZhengYue-Feng, XuQian, FanJia-Hao, CuiXue-Ting, "A novel bacterial foraging optimization algorithm for feature selection," Expert Systems with Applications, vol. 83, pp. 1-17, 2017.

[31] Passino K. M.., "Biomimicry of bacterial foraging for distributed optimization and control," IEEE Control Systems Magazine, pp. 52-67, Jun 2002.

[32] Guang-Yu Zhu, Wei-Bo Zhang, "Optimal foraging algorithm for global optimization," Applied Soft Computing, vol. 51, pp. 294-313, Feb 2017.

[33] S. Mishra, "A hybrid least square-fuzzy bacterial foraging strategy for harmonic estimation," IEEE Transactions on Evolutionary Computation, vol. 9, no. 1, pp. 61-73, 2005.

[34] Om Prakash Verma, Rishi Raj Chopra, A Gupta, "An Adaptive Bacterial Foraging Algorithm for color image enhancement," IEEE Conference on Information Science and Systems (CISS), NJ, SA, Mar 2016, pp. 1- 6.

[35] Mohammadi M., Montazeri, M. \& Abasi, "Bacterial graphical user interface oriented by particle swarm optimization strategy for optimization of multiple type DFACTS for power quality enhancement in distribution system", Journal of Central South University, vol. 24, no. 3, pp. 569-588, Mar 2017.

\section{Appendix 1}

Test system data: Base quantities $-400 \mathrm{KVA}$, Voltage $=400 \mathrm{~V}$, Frequency $=50 \mathrm{~Hz}$,

Wind Generation capacity $=150 \mathrm{KW}$;

Diesel Generation capacity $=150 \mathrm{KW}$;

$\mathrm{PV}$ generation system $=100 \mathrm{KW}$,

Load $=300 \mathrm{KW}$, Load Power Factor $=0.9$, Residential load $-240 \mathrm{KW}$ (static load) Industrial load $-60 \mathrm{KW}$ (dynamic load)

PV- \% Over-sizing factor (of) for inverter sizing $=40 \%, \mathrm{Ki}=1 ; \mathrm{T}=0.002 \mathrm{sec}$;

Induction motor $(60 \mathrm{KW})$; Rs $=0.573 \Omega, \mathrm{Xs}=1.324 \Omega, \mathrm{Rr}=0.628 \Omega, \mathrm{Xr}=1.324 \Omega, \mathrm{Xm}=62.53 \Omega$

EBFA parameter: $\mathrm{Nb}=6 ; \mathrm{Nch}=25 ; \mathrm{Nsw}=5 ; \mathrm{N}_{\mathrm{RP}}=4 ; \mathrm{N}_{\mathrm{ELD}}=2 ; \mathrm{P}_{\mathrm{ED}}=0.25 ; \mathrm{C}_{1}=\mathrm{C}_{2}=1, \mathrm{w}_{\min }=0.4, \mathrm{w}_{\max }=0.9$

\section{Appendix 2}

Reactive power equation of Synchronous generator

$\mathrm{Q}_{\mathrm{SGD}}=\frac{\left(\mathrm{E}_{\mathrm{q}}^{\prime} \mathrm{V} \cos \delta_{\mathrm{S}}-\mathrm{V}^{2}\right)}{\mathrm{X}_{\mathrm{sd}}^{\prime}}$ 
Reactive power equation of Induction Generator

$\mathrm{Q}_{\mathrm{IG}}=\left[\frac{\mathrm{x}_{\mathrm{e}}}{\left[\frac{\mathrm{r}_{\mathrm{r}}^{\prime}}{\mathrm{s}_{\mathrm{l}}}-\left(2 \mathrm{r}_{\mathrm{r}}^{\prime}+\mathrm{r}_{\mathrm{s}}\right)\right]^{2}+\mathrm{x}_{\mathrm{e}}^{2}}\right] \mathrm{V}^{2}$

Reactive power equation of Inverter

$\mathrm{Q}_{\mathrm{INV}}=\frac{\mathrm{V}_{\mathrm{INV}}{ }^{2}-\mathrm{V}_{\mathrm{INV}} \mathrm{V} \cos \delta}{\mathrm{Xc}}$

Nomenclature

VAR Volt-Ampere reactive

EBFA Enhanced Bacteria foraging algorithm

$\mathrm{V}, \mathrm{V}$ IN Load and inverter voltage

$\delta \quad$ phase angle

QCP Reactive power of capacitor bank,

PIN , QIN Inverter active and reactive power

QSG, QIG SG \& IG reactive power

$\Delta \quad$ Small change in variable

$\mathrm{Xm} \quad$ Magnetizing reactance of IG

\section{BIOGRAPHIES OF AUTHORS}

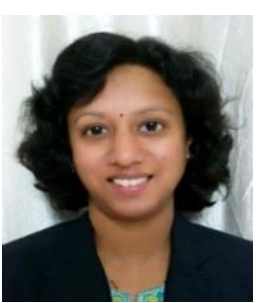

Harsha Anantwar has completed her Master of Engineering in Electrical Engineering with specialization in control system from Pune University, India in 2004. She had worked in Cummins generator Technology UK. She is presently pursing her PhD from Visvesvaraya Technological University Belagavi, Karnataka, India. Her research area of interest includes Voltage control and reactive power management, Distributed Generation, Frequency Control, and Electrical Machines. She is a member of IEEE, Indian Society of Technical Education

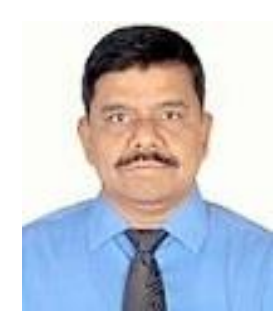

Dr. Shanmukha Sundar has completed M.E. (Electrical Power and Energy Systems) from NIIT suratkal in 1994, Ph. D in optimal Power flow control with FACTS (Electrical Engineering) from Visvesvaraya Technological University, Belagavi, and Karnataka, India in 2010. His areas of interests are Electrical power system, Power Electronics and FACTS controller. He has published several papers in reputed journals and conferences. Currently he is working as Professor and Head of the Electrical Engineering Department, Dayananda Sagar college of Engineering, Bangalore, India

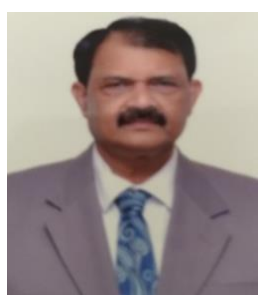

Dr. B.R. Lakshmikantha did his $\mathrm{PhD}$ from Visvesvaraya Technological University, Belagavi, and Karnataka, India in 2008. He is working as Professor and Principal of Dayananda Sagar Academy of Technology and Management- Bangalore, India. He has more than 35 years of teaching experience both at undergraduate and post-graduate level in Electrical Engineering. He is a member of IEEE and Indian Society of Technical Education (ISTE). He has published several research papers in reputed international journals. His main areas of interests are Power System Analysis, Power system Dynamics and Stability, Renewable energy sources, 